\title{
Non-suppressed thyrotropin and elevated thyroglobulin are independent predictors of recurrence in differentiated thyroid carcinoma
}

\author{
Jan Böhm ${ }^{1,2}$, Veli-Matti Kosma ${ }^{2,3}$, Matti Eskelinen ${ }^{4}$, Sinikka Hollmen ${ }^{3}$, Minna Niskanen ${ }^{5}$, Harri Tulla ${ }^{4}$, \\ Esko Alhava ${ }^{4}$ and Leo Niskanen ${ }^{1}$ \\ ${ }^{1}$ Department of Medicine and Clinical Nutrition, University of Kuopio, Finland, ${ }^{2}$ Department of Pathology and Forensic Medicine, University of Kuopio, \\ Finland, ${ }^{3}$ Department of Clinical Pathology, Kuopio University Hospital, Finland, ${ }^{4}$ Department of Surgery, University of Kuopio, Finland and \\ ${ }^{5}$ Department of Anaesthesiology and Intensive Care, Kuopio University Hospital, Finland \\ (Correspondence should be addressed to L Niskanen, Department of Medicine and Clinical Nutrition, Kuopio University Hospital, PO Box 1777, \\ Fin-70211 Kuopio, Finland; Email: Leo.Niskanen@kuh.fi)
}

\begin{abstract}
Objective: Although in most cases differentiated thyroid carcinoma (DTC) responds to surgery and radioiodine (RaI) therapy, some patients will have recurrence and eventually cancer-related death. However, although various prognostic factors of DTC have been identified (e.g. staging, suppressed thyrotropin), none of the previous studies have assessed simultaneously their role in multivariate analysis.

Design and Methods: In this retrospective population-based study, we reviewed the clinicopathological data of 254 DTC patients treated in eastern Finland during the years 1976-1995, for clinical characteristics, primary treatment, follow-up and cancer recurrence. Tumor stage was based on pathological tumor-node-metastasis (pTNM) classification, and histopathological specimens were reevaluated.

Results: DTC recurrence occurred in 33 patients (13\%). In univariate analyses, the predictors of recurrence were older age ( $>60$ years, $P<0.05)$, follicular tumor type $(P<0.01)$, pTNM classification system $(P<0.05)$ and post-ablative radioiodine uptake outside the neck $(P<0.05)$. Non-suppressed serum thyrotropin (TSH) and elevated serum thyroglobulin $(>3 \mu \mathrm{g} / \mathrm{l})$ measured one year after operation were both related to tumor recurrence $(P<0.05$ and $P<0.001$ respectively). In multivariate analysis the independent predictors for recurrence were both elevated thyroglobulin $(P<0.001)$ and non-suppressed TSH $(P<0.05)$ independent of histology, pTNM stage and RaI uptake. Adjusted risk ratio for recurrence of DTC for unsuppressed thyrotropin was 2.3, for elevated thyroglobulin 14.0 and, if both conditions were present, the risk ratio increased to 45.1 .

Conclusion: Our results suggest that both non-suppressed serum TSH and elevated serum thyroglobulin are related to an increased risk of DTC recurrence independent of tumor type and pTNM stage.
\end{abstract}

European Journal of Endocrinology 141 460-467

\section{Introduction}

Differentiated thyroid carcinoma (DTC) is a rather common malignancy with generally favorable prognosis, but it can also be aggressive, leading to recurrent disease or even death. Evidently some patients require aggressive therapy, but their identification remains problematic, and aggressive thyrotropin (TSH) suppression therapy has potential drawbacks, especially on the cardiac and circulatory systems (1) and possibly also on bone mineral density (2).

The tumor-node-metastasis classification (TNM) (3) is a widely accepted classification system for staging of
DTC. When pathological characteristics of primary tumor are available for staging, it is considered as pTNM. So far, scant data are available on the independent prognostic value of pTNM for DTC recurrence. Of the currently available classification systems, pTNM is reported to have the highest prognostic value regarding recurrence-free survival (4). However, in a retrospective analysis, the pTNM was less accurate in predicting relapse-free survival than death (5).

From the other prognostic factors of DTC, the negative post ablative radioiodine (RaI) scan is found to be associated with more favorable prognosis (6). The 
independent prognostic value of this procedure has not yet been defined. One of the clinical goals in the treatment of DTC is to suppress the TSH secretion by levothyroxine $\left(\mathrm{L}-\mathrm{T}_{4}\right)$. Although, theoretically, TSH suppression has evident benefits, the clinical value of TSH suppression in preventing DTC recurrence has, so far, been documented in two studies $(7,8)$. Thyroglobulin ( $\mathrm{Tg}$ ) measurement is an important test in the follow-up of DTC. The presence of thyroglobulin in the serum indicates the persistence of DTC. However, there are some patients whose serum $\mathrm{Tg}$ can be as low as $3 \mathrm{ng} / \mathrm{ml}$ and still have recurrent or metastatic disease (9). The interaction of TSH suppression (treatmentrelated factor) and thyroglobulin (indicator of residual thyroid tissue) has not been assessed.

We have performed a population-based retrospective review and analysis of consecutive series of patients with DTC in order to assess the prognosis of DTC patients. Specifically, we clarified the independent prognostic role of age, stage, tumor infiltrating lymphocytes (TILs), the uptake of RaI, the degree of serum TSH suppression and serum Tg to DTC recurrence.

\section{Subjects and methods}

\section{Patients}

The study population consisted of all consecutive patients with DTC who were treated according to a similar protocol and followed-up between 1976 and 1995 in a defined area in the eastern part of Finland. The total population of the area is 500000 persons, and our data were collected from hospitals that are the only ones that treat thyroid carcinoma in this area. Data files of the Finnish Cancer Registry revealed a total of 373 potential patients with International Classification of Diseases (ICD)-8 (193.99) and ICD-9 (193) codes (10, 11). Those whose clinical follow-up data were inadequate or were for less than 6 months, whose pathological specimens were not available or were not confirmed at re-evaluation, were excluded. Formation of the study population is illustrated by the flow diagram in Fig. 1 .

All the relevant patient records were reviewed for tumor characteristics, metastases, primary treatment and follow-up, and cancer recurrence. Evidence of recurrence was based on either ultrasound, RaI or magnetic resonance image findings and recurrence was defined as a new evidence of local disease or distant metastases occurring more than 6 months after the primary operation (12). Tumor stage was assessed retrospectively according to the pTNM classification system based on the 1987 International Union Against Cancer (UICC) classification (3).

\section{Treatment}

All the patients in this study underwent thyroidectomy. The type of operation was total or near total

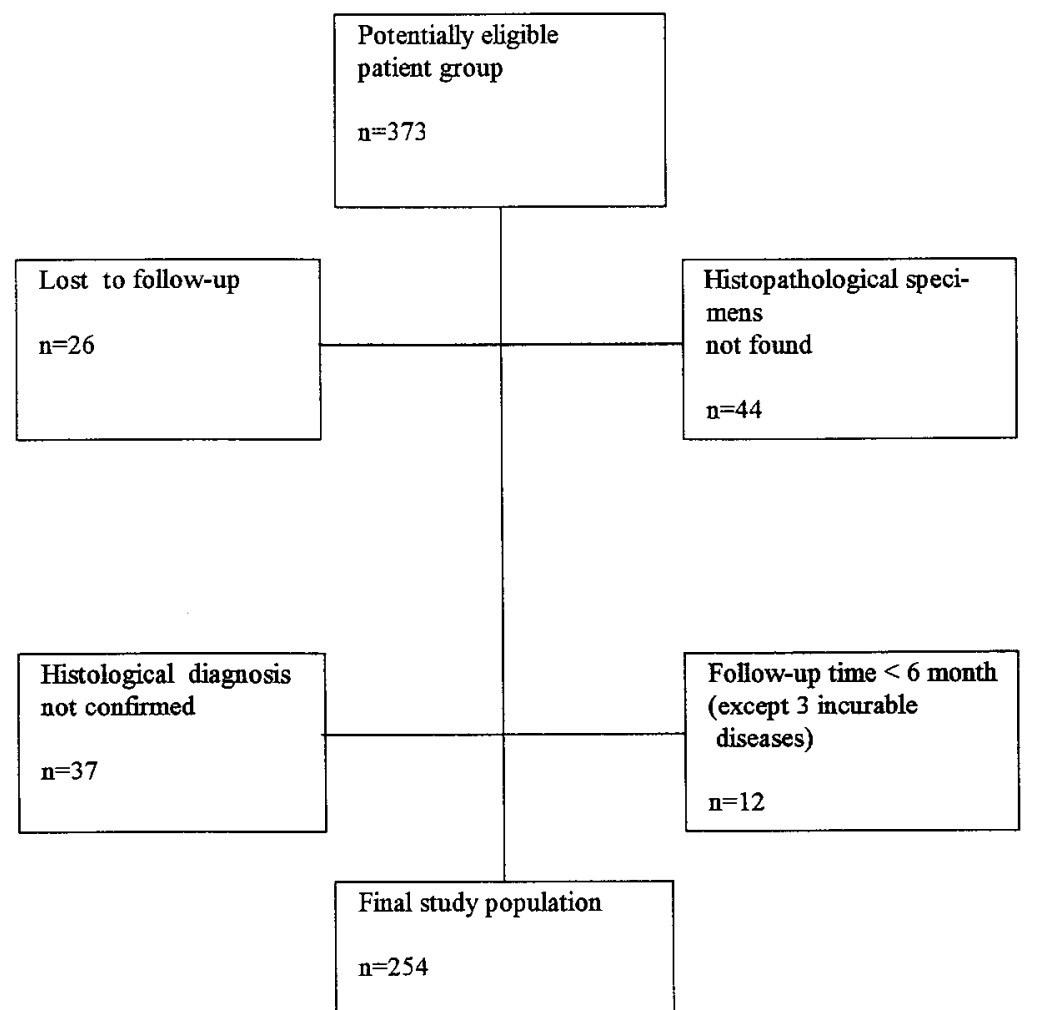

Figure 1 Formation of the study population. 
thyroidectomy in $219(86 \%)$ patients, palliative resection in $18(7 \%)$ patients, and $12(5 \%)$ patients whose quality of operation could not be assessed from the patients' files. The standard procedure was always to perform as complete a thyroidectomy as possible. Hemithyroidectomy was performed on $5(2 \%)$ patients with occult DTC. After surgical operation, a low-dose RaI scan was performed. The ablation therapy was given if there was an accumulation of radioiodine. The whole-body scan was performed a few days after RaI ablation and the uptake was recorded. In our study group, 198 (78\%) patients received radioiodine ablation therapy. Fifty-eight patients received ablation therapy twice or more. The median of post-operative radioiodine ablation dose was $105 \mathrm{mCi}$ (mean 105.4 and mode $80 \mathrm{mCi}$, range $50-150 \mathrm{mCi}$ ). After these procedures the TSH suppression treatment with thyroxine was started for every patient to prevent tumor residual growth.

\section{TSH and thyroglobulin}

From 1976 to 1981, serum TSH was determined using the TSH radioimmunoassay (RIA) kit (Amersham, Amersham, Bucks, UK) and from 1981 to 1986 using the TSH $\left({ }^{125} \mathrm{I}\right)$ RIA kit (Farmos Diagnostica, Turku, Finland). After 1986, the Spectria TSH immunoradiometric assay (IRMA) ${ }^{125}$ I kit (Farmos Diagnostica) was used. The suppression of serum TSH one year after operation was defined as $\leq 1.0 \mathrm{mU} / \mathrm{l}$ and/or no response to thyrotropin releasing hormone (TRH) during the years 1976-1986, and as serum TSH $\leq 0.1 \mathrm{mU} / \mathrm{l}$ during 1986-1995. Two hundred micrograms TRH were given i.v. and the levels of TSH were measured at zero time and $20 \mathrm{~min}$ and $30 \mathrm{~min}$ after TRH administration. TSH was considered suppressed when the difference between TSH values at baseline and 20 min after injection was lower than $2 \mathrm{mU} / \mathrm{l}(7)$.

Likewise, serum thyroglobulin was assessed one year after operation. Serum thyroglobulin values were determined in a central laboratory (Oy Medix Ab, Kauniainen, Finland) using an RIA kit (HTGK2, Biosorin, Saluggia, Italy). The cut-off level was $3 \mu \mathrm{g} / \mathrm{l}$; levels over that were considered elevated. Thyroglobulin was measured during the follow-up on $\mathrm{L}_{-} \mathrm{T}_{4}$ treatment. All thyroglobulin measurements were checked for interfering serum antibodies and due to their presence six patients were excluded from the analyses concerning serum thyroglobulin.

\section{Histopathological classification}

Two experienced histopathologists (V-M K and S H) reexamined hematoxylin and eosin stained sections simultaneously, being unaware of the clinical data. Histopathological diagnosis was confirmed by reviewing one to four original sections of the primary tumor.

Papillary carcinomas were subdivided as common type, follicular variant and occult carcinomas. Follicular carcinomas were subdivided as minimally invasive or widely invasive.

The infiltration of lymphocytes and plasma cells in close vicinity of the tumor as well as inside the tumor area were estimated from all the papillary carcinoma specimens and graded as absent or present. Histopathological specimens of different metastases were also reviewed.

\section{Statistical analysis}

The SPSS program package (SPSS Inc., Chicago, IL, USA) was used for statistical analyses. The association between the tumor recurrence and other factors was tested by Mantel-Haenzel or Pearson chi-square tests. Cox regression model was used for multivariate analyses. A $P$ value $<0.05$ was considered statistically significant. The relapse-free survival was defined as the time from surgical resection to the time of cancer recurrence. Life tables were constructed using an actuarial method which takes into account the differences in actual observation periods (13). The expected five-year mortality rate of DTC patients was determined by adjusting the general population of the same geographical area by gender and age to the DTC patients. When comparing the outcome of DTC patients with the general population, the standardized mortality ratio (the ratio between the actuarial and expected mortality) was used to express the increased mortality.

\section{Results}

\section{Clinical characteristics}

Clinical characteristics of the study population are shown in Table 1 according to DTC recurrence. Women outnumbered men, and the mean follow-up time of the study population was 7.2 years, with a range of less than 1 year to 20 years. Histopathological re-examination confirmed the diagnosis of 216 papillary and 38 follicular carcinomas. The mean age at diagnosis was 46.8 years (range 8-92 years) for papillary and 61.6 years (range 27-84 years) for follicular carcinoma.

\section{Predictors of the recurrence of DTC}

Univariate analyses Thirty-three out of two hundred and fifty-four patients had local or distant recurrences (13\%) (Table 1).

In univariate analyses, the gender did not predict the recurrence of DTC. The mean age of the whole study group was 49.0 years, but the frequency of older patients ( $>60$ years) was markedly higher in those with recurrence than in those without $(39 \%$ vs $23 \%$, $P<0.05)$. Likewise, the follicular type of tumor was associated with a higher risk of tumor recurrence 
Table 1 Characteristics of study population according to the recurrence (REC) of DTC. Number of patients with percentage in parentheses are given.

\begin{tabular}{|c|c|c|c|}
\hline & REC - $(n=221)$ & $\mathbf{R E C}+(n=33)$ & $P$ value \\
\hline \multicolumn{4}{|l|}{ Gender } \\
\hline Men & $35(16)$ & $9(27)$ & \multirow[t]{2}{*}{0.1} \\
\hline Women & $186(84)$ & 24 (73) & \\
\hline \multicolumn{4}{|l|}{ Age } \\
\hline$\leq 60$ years & $170(77)$ & $20(61)$ & \multirow[t]{2}{*}{$<0.05$} \\
\hline$>60$ years & 51 (23) & $13(39)$ & \\
\hline \multicolumn{4}{|l|}{ Histology } \\
\hline Papillary & $193(87)$ & $23(70)$ & \multirow[t]{2}{*}{$<0.01$} \\
\hline Follicular & $28(13)$ & $10(30)$ & \\
\hline \multicolumn{4}{|l|}{ Tumor size } \\
\hline $\mathrm{T}_{1}: \leq 10 \mathrm{~mm}$ & $42(20)$ & $3(9)$ & \multirow[t]{4}{*}{$<0.001$} \\
\hline $\mathrm{T}_{2}: 10-40 \mathrm{~mm}$ & $124(58)$ & $11(33)$ & \\
\hline $\mathrm{T}_{3}:>40 \mathrm{~mm}$ & $15(7)$ & $8(24)$ & \\
\hline $\mathrm{T}_{4}$ : extra thyroidal invasion & $34(16)$ & $11(33)$ & \\
\hline \multicolumn{4}{|l|}{ Nodal metastases } \\
\hline $\mathrm{N}_{0}$ : negative & $182(85)$ & $18(56)$ & \multirow{3}{*}{$<0.001$} \\
\hline $\mathrm{N}_{1 \mathrm{a}}$ : ipsilateral & $24(11)$ & $11(35)$ & \\
\hline $\mathrm{N}_{1 \mathrm{~b}}:$ bilateral & $8(4)$ & $3(9)$ & \\
\hline \multicolumn{4}{|l|}{ Distant metastases } \\
\hline $\mathrm{M}_{0}$ : negative & 207 (95) & $25(81)$ & \multirow[t]{2}{*}{$<0.01$} \\
\hline$M_{1}$ : positive & $11(5)$ & $6(19)$ & \\
\hline \multicolumn{4}{|l|}{ Stage } \\
\hline 1 & $119(56)$ & $12(40)$ & \multirow[t]{4}{*}{$<0.05$} \\
\hline II & $63(30)$ & $9(30)$ & \\
\hline III & $22(10)$ & $5(17)$ & \\
\hline IV & $8(4)$ & $4(13)$ & \\
\hline \multicolumn{4}{|l|}{ Papillary carcinoma } \\
\hline \multicolumn{4}{|l|}{ Inflammatory cell infiltration } \\
\hline Absent & $108(56)$ & $15(65)$ & \multirow[t]{2}{*}{0.13} \\
\hline Present & $85(44)$ & $8(35)$ & \\
\hline \multicolumn{4}{|l|}{ Subtype } \\
\hline Common type & $141(73)$ & $16(70)$ & \multirow[t]{3}{*}{0.20} \\
\hline Occult & $25(13)$ & $1(4)$ & \\
\hline Follicular variant & 27 (14) & $6(26)$ & \\
\hline \multicolumn{4}{|l|}{ Follicular carcinoma } \\
\hline Invasion type & & & \multirow{3}{*}{0.84} \\
\hline Minimally invasive & $10(37)$ & $3(33)$ & \\
\hline Widely invasive & $17(63)$ & $6(67)$ & \\
\hline
\end{tabular}

For explanation of Stage I, II, III, IV see reference (3).

$(P<0.01)$. Most of the tumors $(54 \%)$ were $1-4 \mathrm{~cm}$ in diameter and the size of the tumor was also related to the higher risk of tumor recurrence $(P<0.001)$. Histology revealed 46 patients $(19 \%)$ with nodal metastasis and $17(7 \%)$ patients with distant metastasis. The presence of nodal and distant metastases was predictive of recurrent disease $(P<0.001$ and $P<0.01$ respectively). Higher stage of tumor was found to be associated with higher incidence of tumor recurrence $(P<0.05)$. The degree of inflammatory cell infiltration in tumor tissues did not associate with cancer recurrence.

The non-suppressed TSH one year after the primary operation was related to higher risk of tumor recurrence $(P<0.05)$ (Fig. 2). In univariate analysis, the strongest predictor for tumor recurrence was the elevated serum thyroglobulin $(>3 \mu \mathrm{g} / \mathrm{l})($ median 21.0 , range $4-5684 \mu \mathrm{g} / \mathrm{l})$ measured one year postoperatively $(71 \%$ vs $14 \%$, $P<0.001$ ) (Fig. 3). Fifteen patients had elevated serum thyroglobulin level at the same time as unsuppressed TSH. Eight (53\%) of these patients had recurrence during the follow-up.

The RaI uptake after the first ablative dose was observed in the neck in $156(90 \%)$ patients and also elsewhere in 24 patients $(11 \%)$. The RaI uptake in the neck was not predictive of recurrence, but uptake outside the neck increased the risk significantly $(P=0.01)$.

Multivariate analyses In multivariate analysis $(n=132$, including age, gender, treatment center, tumor type, stage, RaI uptake, TSH suppression and serum thyroglobulin), the strongest predictor for DTC recurrence was elevated serum thyroglobulin $(P<0.001)$ and serum TSH suppression $(P<0.05)$ (Table 2). The analysis was performed after exclusion of subjects with occult DTC and the conclusion regarding main risk factors remained identical (data 


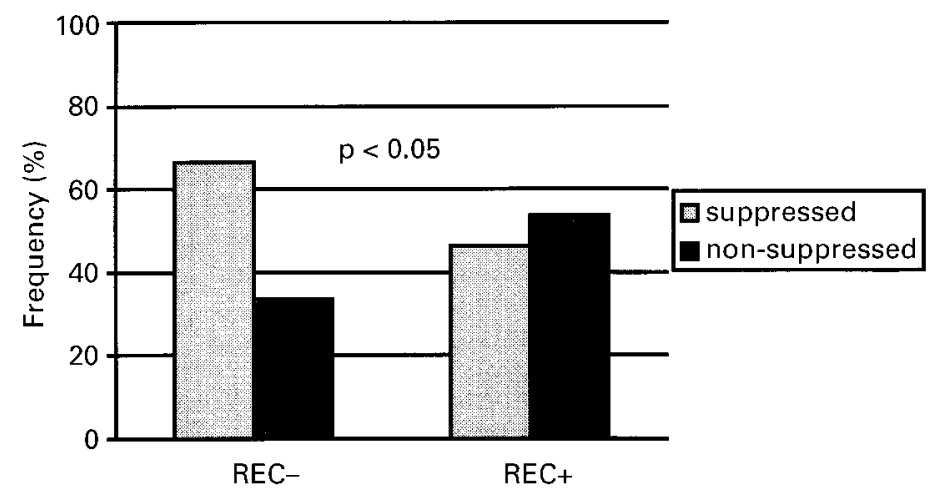

Figure 2 Frequencies of suppressed serum TSH one year after operation in patients with recurrence (REC +$)(n=28)$ and in those without recurrence (REC-) $(n=185)$ during the follow-up. $P$ value is shown. not shown). In order to further illustrate the impact of serum TSH and thyroglobulin on the risk of recurrence of DTC, Fig. 4 here shows that the risk ratio (adjusted for age, sex and stage) for elevated TSH alone (without elevated serum thyroglobulin) was 2.23 (95\% confidence interval (CI) 0.36-13.90), for thyroglobulin alone (with suppressed serum TSH) 13.96 (95\% CI 3.30-59.08) and for both conditions (elevated serum TSH and thyroglobulin) the risk ratio increased markedly (up to $45.11,95 \%$ CI $7.54-269.84$ ).

\section{Mortality of patients with DTC}

All-cause mortality as compared with the general population Twenty-four patients $(9.4 \%)$ died within 5 years after the primary operation, and the actuarial mortality was $11.2 \%$ (28 deaths). The standardized mortality ratio was 1.2 (28 actuarial deaths/23 expected deaths; CI 0.71 to 2.02).

Predictors of disease-specific and all-cause mortality in patients with DTC Twenty-three patients $(9,1 \%)$ died because of DTC during the follow-up. Type of tumor, age older than 60, TNM stage and serum thyroglobulin level were strongly associated with cancer-related and all-cause mortality. In addition, gender and TSH suppression were associated only with all-cause mortality, and post-ablative RaI uptake with cancer-related mortality (Table 3 ).

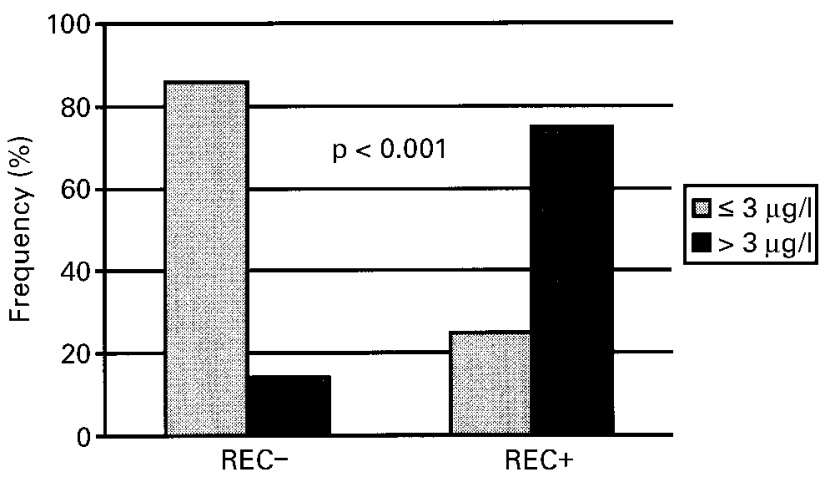

\section{Discussion}

The data provided by this study reveal that the serum thyroglobulin and serum TSH suppression are both statistically independent predictors of DTC recurrence, despite adjusting for age, gender, and pTNM stage. The older age ( $>60$ years), the type of tumor, post ablative RaI uptake and pTNM stage were related to the increased incidence of DTC recurrence. In addition, our patients' characteristics are comparable to previous hospital or register based cohorts $(7,14)$. Moreover, female-to-male ratio, percentage of follicular tumors or frequency of recurrences in our study group do not differ markedly from previous studies $(7,15,16)$.

The histology of the tumor is one of the major prognostic factors identified. The follicular type of tumor is reported to have a poorer prognosis than the papillary type $(12,17)$. However, after controlling for other factors, the type of tumor was not an independent predictor for DTC recurrence in the present study. Frequent occurrence of focal lymphocytic infiltration in the thyroid gland is documented in papillary thyroid carcinoma patients (18). Matsubayashi et al. (19) found that lymphocytic infiltration of the tumor was related to favorable prognosis in 95 Japanese patients, which contradicts the results of Kamma et al. (20). The mean age of our patients was closer to that of patients studied by Matsubayashi et al. (19), but we could not show any significant difference between TILs and tumor recurrence.

Figure 3 Frequencies of serum thyroglobulin levels one year after operation in patients with recurrence (REC +$)(n=20)$ and in those without recurrence (REC-) $(n=143)$ during the follow-up. $P$ value is shown. 
Table 2 Multivariate analysis for the recurrence of DTC.

\begin{tabular}{|c|c|c|c|}
\hline & Hazards ratio & $95 \% \mathrm{Cl}$ & $P$ value \\
\hline \multicolumn{4}{|l|}{ Age } \\
\hline$(\leq 60 \mathrm{yr}=0,>60 \mathrm{yr}=1)$ & 0.41 & $(0.07-2.24)$ & 0.301 \\
\hline Gender & & & \\
\hline$(0=$ man, $1=$ woman $)$ & 2.24 & $(0.40-12.48)$ & 0.357 \\
\hline \multicolumn{4}{|l|}{ Histology } \\
\hline$(0=$ papillary, $1=$ follicular $)$ & 0.75 & $(0.11-5.31)$ & 0.771 \\
\hline \multicolumn{4}{|l|}{ Stage } \\
\hline I & Reference & & 0.229 \\
\hline II & 4.42 & $(0.96-20.43)$ & 0.057 \\
\hline III & 1.95 & $(0.26-14.87)$ & 0.519 \\
\hline IV & 6.12 & $(0.60-62.21)$ & 0.126 \\
\hline \multicolumn{4}{|l|}{ Ral uptake } \\
\hline$(0=$ no, $1=$ yes $)$ & 0.89 & $(0.08-9.92)$ & 0.922 \\
\hline \multicolumn{4}{|l|}{ TSH suppression } \\
\hline$(0=$ no, $1=$ yes $)$ & 3.46 & $(1.02-11.74)$ & 0.046 \\
\hline \multicolumn{4}{|l|}{ Thyroglobulin level } \\
\hline$(\leq 3 \mu \mathrm{g} / \mathrm{l}=\mathrm{no},>3 \mu \mathrm{g} / \mathrm{l}=\mathrm{yes})$ & 12.28 & $(3.55-42.41)$ & $<0.001$ \\
\hline \multicolumn{4}{|l|}{ Treatment center } \\
\hline$(0=$ Kuopio, $1=$ others $)$ & 0.38 & $(0.08-1.73)$ & 0.213 \\
\hline
\end{tabular}

For explanation of Stage I, II III, IV see reference (3).

Several studies $(14,15,21)$ have shown that an unfavorable outcome is associated with age. We found that age over 60 years was related to a higher risk of tumor recurrence and cause-specific mortality, confirming previous findings $(14,17)$. The size of the tumor and the presence of distant metastases were strongly linked with the recurrence of tumor in the current study. These tumor characteristics have been confirmed to be related to unfavorable outcome in several reports $(12,14,21)$. The pTNM staging system is considered to be a useful system for discriminating the high and low risk patients. Loh et al. (12) have performed a retrospective analysis of 700 patients with DTC. They found the pTNM staging system to be an independent prognostic factor for tumor recurrence. However, serum TSH suppression or serum thyroglobulin levels were not taken into account in their analysis. We found that the pTNM stage associated with poor outcome, although it was not an independent prognostic factor for relapse-free survival.

TSH increases adenylate cyclase activity and cAMP levels in vitro, thereby leading to thyroid cell growth (22). The clinical value of TSH suppression has been documented by a retrospective study by Pujol et al. (7).
They showed that the difference between constantly suppressed TSH and unsuppressed TSH increases the risk of recurrence significantly whatever the cut-off value $(0.05-0.1 \mathrm{mU} / \mathrm{l})$ used for defining TSH suppression. TSH suppression was also an independent predictor of relapse-free survival in their study. The minor draw-back of our study was that serum TSH was evaluated from one point only. However, the tolerability to suppressive therapy with $\mathrm{L}_{-} \mathrm{T}_{4}$ is evident 1 year after treatment and only minor fluctuations (data not shown) were seen with a longer follow-up. This single point assessment, if anything, will lead to a conservative estimate of the true association. Thus, our study is in agreement with the findings of Pujol et al. (7) and further implies that the role of TSH suppression is statistically independent even after taking serum thyroglobulin into account. However, at present the optimal degree of TSH suppression by ultrasensitive TSH measurement is not known (23). We assume that one of the reasons for unsuppressed TSH in the present study was poor tolerance of suppressive $\mathrm{L}_{-} \mathrm{T}_{4}$ doses, which can cause thyrotoxic symptoms such as weight loss and heart arrhythmias (1).
Figure 4 Risk ratios for the recurrence of DTC (Cox regression analysis) for non-suppressed TSH only, elevated thyroglobulin only and for both occurring simultaneously.

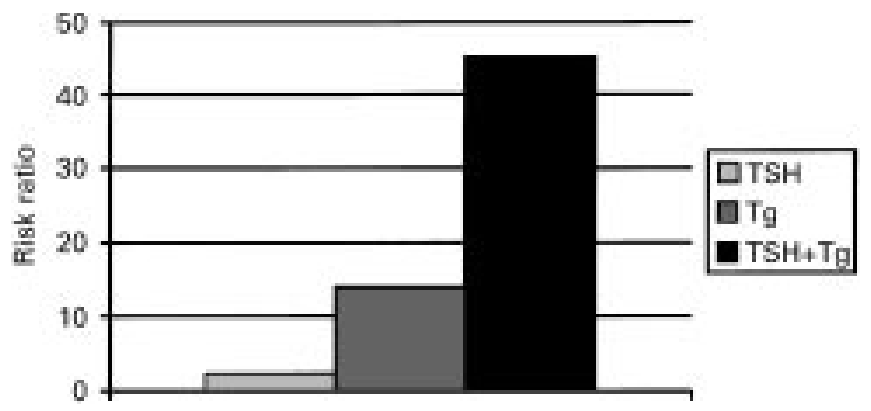


Table 3 Risk factors for all-cause mortality (ACM) and cancer-related mortality (CRM). The number of patients with percentage in parentheses are given.

\begin{tabular}{|c|c|c|c|c|c|c|}
\hline & & $\mathrm{ACM}$ & & & CRM & \\
\hline & $+(n=40)$ & $-(n=214)$ & $P$ value & $+(n=23)$ & $-(n=231)$ & $P$ value \\
\hline Histology & & & & & & \\
\hline Papillary & $24(60)$ & $192(90)$ & $<0.001$ & $13(56)$ & $203(88)$ & $<0.001$ \\
\hline Follicular & $16(40)$ & $22(10)$ & & $10(44)$ & $28(12)$ & \\
\hline Age & & & & & & \\
\hline$\leq 60$ years & $8(20)$ & $182(15)$ & $<0.001$ & $3(13)$ & $187(81)$ & $<0.001$ \\
\hline$>60$ years & $32(80)$ & $32(85)$ & & $20(87)$ & $44(19)$ & \\
\hline Sex & & & & & & \\
\hline Male & $12(30)$ & $32(15)$ & $<0.05$ & $6(26)$ & $38(17)$ & 0.2 \\
\hline Female & $28(70)$ & $182(85)$ & & $17(74)$ & $193(83)$ & \\
\hline Stage & & & & & & \\
\hline 1 & $2(6)$ & $129(62)$ & $<0.001$ & $0 \quad(0)$ & $131(58)$ & $<0.001$ \\
\hline II & $11(33)$ & $61(29)$ & & $3(18)$ & 69 (31) & \\
\hline III & $11(33)$ & $16(8)$ & & $5(29)$ & $22(10)$ & \\
\hline IV & $9(27)$ & $3(1)$ & & $9(53)$ & $3(1)$ & \\
\hline TSH suppression & & & & & & \\
\hline Suppressed & $13(46)$ & $123(66)$ & $<0.05$ & $6(43)$ & $130(65)$ & 0.09 \\
\hline Unsuppressed & $15(54)$ & $62(34)$ & & $8(57)$ & $69(35)$ & \\
\hline Thyroglobulin & & & & & & \\
\hline$\leq 3 \mu \mathrm{g} / \mathrm{l}$ & $3(23)$ & $125(83)$ & $<0.001$ & $1(11)$ & $127(83)$ & $<0.001$ \\
\hline$>3 \mu \mathrm{g} / \mathrm{l}$ & $10(77)$ & $25(17)$ & & $8(89)$ & $27(17)$ & \\
\hline Ral uptake & & & & & & \\
\hline No uptake & $4(12)$ & $10(6)$ & 0.07 & $1 \quad(5)$ & $13(7)$ & $<0.001$ \\
\hline Uptake in the neck & $20(59)$ & $136(85)$ & & $8(42)$ & $148(85)$ & \\
\hline Distal uptake & $10(29)$ & $14(9)$ & & $10(53)$ & $14(8)$ & \\
\hline
\end{tabular}

For explanation of Stage I, II III, IV see reference (3).

Serum thyroglobulin has been proven to be a sensitive tumor marker in DTC after RaI ablation therapy (24). In our analyses, thyroglobulin values measured during $\mathrm{L}-\mathrm{T}_{4}$ treatment were used. The sensitivity of thyroglobulin measurement decreases but specificity increases compared with values measured when off $\mathrm{L}-\mathrm{T}_{4}$ treatment (25). When on $\mathrm{L}-\mathrm{T}_{4}$ therapy, a consistent level of $2 \mu \mathrm{g} / \mathrm{l}$ during the follow-up period has proved to be highly indicative of the cancer-free state, although only a minority of patients meets this criteria (9). Our cut-off value for serum thyroglobulin level was $3 \mu \mathrm{g} / \mathrm{l}$, which has also been used in some other studies $(7,25,26)$. In our study, one year after operation, 35 patients $(21 \%)$ had thyroglobulin over $3 \mu \mathrm{g} / \mathrm{l}$, of whom $15(43 \%)$ had recurrent disease. In multivariate analysis, the elevated serum thyroglobulin proved to be the most powerful independent predictor for tumor recurrence.

Theoretically, patients with DTC are exposed not only to the risk of recurrence of the cancer, but also to subclinical hyperthyreosis, which may have adverse effects on bone and cardiac and circulatory systems, as well as multiple high dose RaI therapies which may potentially cause increased mortality $(1,27)$. To assess the possible excess mortality associated with DTC, we used as a control group the general population of eastern Finland. In the current study the mortality rate of DTC patients was only 1.2 times that of the general population. Our follow-up time for survival analysis was five years which is a rather limited time to assess DTC mortality. Deaths caused by DTC are reported to occur for 40 years after primary treatment (16). Our ageadjusted survival analysis shows that mortality caused by DTC tended to increase slightly for 4 years after primary treatment decreasing subsequently almost to the same level as the mortality of the general population. In the present study a slight increase in mortality seems to be caused by DTC itself rather than by treatment procedures.

In conclusion, both serum thyroglobulin level and serum TSH suppression one year after primary treatment are independent prognostic factors for DTC recurrence. Our results confirm the role of age, type of tumor, distal RaI uptake and TNM stage of primary tumor as predictors of DTC recurrence. Finally, DTC does not cause a statistically significant increase in all-cause mortality as compared with the general population.

\section{References}

1 Biondi B, Fazio S, Carella C, Amato G, Cittadini A, Lupoli G et al. Cardiac effects of long-term thyrotropin-suppressive therapy with levothyroxine. Journal of Clinical Endocrinology and Metabolism $199377334-338$.

2 Faber J \& Galloe AM. Changes in bone mass during prolonged subclinical hyperthyroidism due to L-thyroxine treatment: a meta-analysis. European Journal of Endocrinology 1994130 350-356.

3 UICC: TNM Classification of Malignant Tumors, edn 4, pp. 33-35. Eds P Hermanek \& LH Sobin. Berlin: Springer-Verlag, 1987. 
4 Sherman SI, Brierley JD, Sperling M, Ain KB, Bigos ST, Cooper DS et al. Prospective multicenter study of thyroid carcinoma treatment: initial analysis of staging and outcome. Cancer 1998 83 1012-1021.

5 Salvesen H, Njolstad PR, Akslen LA, Albrektsen G, Soreide O \& Varhaug JE. Papillary thyroid carcinoma: a multivariate analysis of prognostic factors including an evaluation of the p-TNM staging system. European Journal of Surgery 1992158 583-589.

6 Pupi A, Castagnoli A, Morotti A, Giuseppe L \& Meldolesi U. Prognostic value of the ${ }^{131} \mathrm{I}$ whole-body scan in postsurgical therapy for differentiated thyroid cancer. Cancer 198352 439441.

7 Pujol P, Daures J-P, Nsakala N, Baldet L, Bringer J \& Jaffiol L. Degree of thyrotropin suppression as a prognostic determinant in differentiated thyroid carcinoma. Journal of Clinical Endocrinology and Metabolism $1996124318-4322$.

8 Cooper DS, Specker B, Ho M, Sperling M, Ladenson PW, Ross DS et al. Thyrotropin suppression and disease progression in patients with differentiated thyroid cancer: results from the National Thyroid Cancer Treatment Cooperative Registry. Thyroid 19988 737-744.

9 Ozata M, Suzuki S, Miyamoto T, Tsuan Liu R, Fierro-Renoy F \& DeGroot LJ. Serum thyroglobulin in the follow-up of patients with treated differentiated thyroid cancer. Journal of Clinical Endocrinology and Metabolism 199479 98-105.

10 WHO. International Classification of Diseases, Eighth Review, vol 2 , p 117. Geneva: World Health Organization, 1968.

11 WHO. International Classification of Diseases, Ninth Review, vol 2, p 367. Geneva: World Health Organization, 1978.

12 Loh K-C, Greenspan FS, Gee L, Miller TR \& Yeo PPB. Pathologic tumor-node-metastasis (pTNM) staging for papillary and follicular thyroid carcinomas: a retrospective analysis of 700 patients. Journal of Clinical Endocrinology and Metabolism 199782 35533562 .

13 Norusis MJ. SPSS Inc: SPSS ${ }^{\circledR}$ for Unix ${ }^{\circledR}$ : Advanced Statistics, Release 5.0. Chicago: SPSS, 1993.

14 Tsang RW, Brierley JD, Simpson WJ, Panzarella T, Gospodarowicz M K \& Sutcliffe SB. The effects of surgery, radioiodine, and external radiation on the clinical outcome of patients with differentiated thyroid carcinoma. Cancer 199882 375-388.

15 Gemsenjäger E, Heitz PU \& Benedict M. Selective treatment of differentiated thyroid carcinoma. World Journal of Surgery 1997 21 546-552.

16 Tubiana M, Schlumberger M, Rougier P, Laplanche A, Benhamou $\mathrm{E}$, Gardet $\mathrm{P}$ et al. Long-term results and prognostic factors in patients with differentiated thyroid carcinoma. Cancer 198555 794-804.
17 Simpson WJ, McKinney SE, Carruthers JS Gospodarowicz MK, Sutcliffe SB \& Panzarella T. Papillary and follicular thyroid cancer: prognostic factors in 1578 patients. American Journal of Medicine $198783479-488$.

18 Aguayo J, Sakatsume Y, Jamieson C, Row VV \& Volpe R. Nontoxic nodular goiter and papillary thyroid carcinoma are not associated with peripheral blood lymphocyte sensitization to thyroid cells. Journal of Clinical Endocrinology and Metabolism 198968 145149.

19 Matsubayashi S, Kawai K, Matsumoto Y, Mukuta T, Morita T, Hirai K et al. The correlation between papillary thyroid carcinoma and lymphocytic infiltration in the thyroid gland. Journal of Clinical Endocrinology and Metabolism 199580 3421-3424.

20 Kamma H, Fujii K \& Ogata T. Lymphocytic infiltration in juvenile thyroid carcinoma. Cancer 198862 1988-1993.

21 Shah JP, Loree TR, Dharker D, Strong EW, Begg C \& Vlamis V. Prognostic factors in differentiated carcinoma of the thyroid gland. American Journal of Surgery 1992164 658-661.

22 Carayon P, Thomas-Morvan C, Castanas E \& Tubiana M. Human thyroid cancer: membrane thyrotropin binding and adenylate cyclate activity. Journal of Clinical Endocrinology and Metabolism $198051915-920$.

23 Burmeister LA, Goumaz MO, Mariash CN \& Oppenheimer JH. Levothyroxine dose requirements for thyrotropin suppression therapy in treatment of differentiated thyroid cancer. Journal of Clinical Endocrinology and Metabolism 199275 344-350.

24 Schlumberger M, Fragu P, Parmentier C \& Tubiana M. Thyroglobulin assay in the follow-up of patients with differentiated thyroid carcinomas: comparison of its value in patients with or without normal residual tissue. Acta Endocrinologica 1981 $98215-221$.

25 Müller-Gärtner HW \& Schneider C. Clinical evaluation of tumor characteristics predisposing serum thyroglobulin to be undetectable in patients with differentiated thyroid cancer. Cancer 1988 $61976-981$.

26 Pacini F, Fugazzola L, Lippi F, Ceccarelli C, Centoni R, Miccoli P et al. Detection of thyroglobulin in fine needle aspirates of nonthyroidal neck masses: a clue to the diagnosis of metastatic differentiated thyroid cancer. Journal of Clinical Endocrinology and Metabolism 199274 1401-1404.

27 Franklyn JA, Maisonneuve P, Sheppard MC, Betteridge J \& Boyle P. Mortality after the treatment of hyperthyroidism with radioactive iodine. New England Journal of Medicine 1998338 712-718.

Received 10 February 1999

Accepted 2 July 1999 